\title{
President's address 2012
}

JACQUELINE ROWARTH

Professor of Agribusiness, The University of Waikato, Hamilton

\section{We live in interesting times.}

The words above used to be associated with a Chinese curse but now "interesting times" are simply life as we know it. The past 12 months in global agriculture have encompassed rapidly changing commodity prices, floods, fires, tsunamis, earthquakes, the emissions trading scheme discussions, statements about water quality and debates on alternative product and farm ownerships. Resilience is increasingly the call, at the same time as farmers are being urged to increase productivity by adopting new technologies whilst living within increasingly stringent regulations.

A remarkable number of reports containing implications for agriculture have been released over the last few months addressing the same issues from different perspectives. Bringing them together indicates a role for New Zealand agriculture beyond that of increasingly efficient food productivity - also known as Business As Usual (BAU). The challenge, as always, is how to achieve that role.

\section{The Call to Arms}

BAU is insufficient to achieve the Government's Economic Growth Agenda which targets a huge increase in the real value of agri-food exports by 2025 - from \$20 billion to \$58 billion (in 2009 figures). A compound annual growth rate of approximately $7 \%$ would be required to achieve the target, but business as usual would suggest 3\%. Professor Mike Boland, Principal Scientist for the Riddet Institute, calculates that another $1 \%$ of productivity is achievable through implementation of currently available "improvements", but there is still a gap of $3 \%$.

The problem has been outlined in A Call to Arms: a contribution to a New Zealand agri-food strategy, released in July by The Riddet Institute (a Centre of Research Excellence based at Massey University and involving The University of Auckland, AgResearch, Plant and Food Research and the University of Otago). The "call" pointed out that lifting performance will require research and recommended a trebling of research intensity in agri-foods within 5 years.

This is not a new idea.

Increasing research investment and targeting research towards the productive part of the economy has been urged repeatedly by presidents of this association as well as many others. The problem continues to be that
New Zealand has a poorly-funded research system which is constantly under-going restructuring. It is very difficult for scientists to have time to think, and equally difficult to achieve money for the sort of long-term trials that are required for agriculture. Overall there continues to be concern that research and development $(R \& D)$, and agriculture, are not high priorities in government circles. The creation of the super-ministry this year "Business, Innovation and Employment", which encompasses science, research and technology, and the Ministry for Primary Industries, which encompasses agriculture, supports this concern.

Continued investment in research, even in times of plenty, is important because the results take time to appear. Professor Julian Alston, Department of Agriculture and Resource Economics, University of California, Davis, calculates (from almost 300 research publications covering almost 1900 observations) that research costs are maximised in the years $2-8$ of a research project, with benefits escalating from years 8 to 15 . Most benefits accrue during years $15-25$, and then benefits decline. FAO statisticians believe that the global reduction in investment in agricultural $R \& D$ in the 1980s and 90s is part of the reason for current food insecurity - we aren't benefitting from the increase in production now that could have occurred if there had been more investment in the past.

\section{Food Security}

Food security is a global issue because increases in food production aren't keeping up with population growth, and climatic events (such as hurricanes, floods and drought) are affecting harvests unpredictably. The perturbations have resulted in huge price swings in food commodities in the last few years, with "food riots" in many countries and on-going grumbling about the price of food. The latter is occurring even though the evidence indicates that food expenditure as a proportion of household income is smaller than ever; expectations of cheap food in developed countries matches the entitlement to holidays, cars and flatscreen TVs... Because of deals, the true price of most things is hidden. For food, the fact that the supermarket return on invested capital is $16 \%$ (Standard and Poor's estimate), including loss leaders, means that supermarkets will always win in a negotiation with a supplier... remembering that the return on invested capital for 
sheep and beef is in the order of $2-3 \%$ and that for dairy is $4-5 \%$.

The Global Food Security Index, produced by The Economist Intelligence Unit, encompasses affordability, availability and quality of food in 105 countries and is an attempt to "deepen the dialogue on food insecurity and to measure the risks in a consistent, rigorous framework". The three dimensions chosen, affordability, availability and utilisation (quality and safety), are those identified in the Rome Declaration on World Food Security in 1996 by the World Health Organisation. The Index 2012 ranks New Zealand 11th, behind the US, Denmark, Norway and France. This ranking is despite the fact that New Zealand produces over 4 times as much food as we can or should eat on a calorific basis, and over 10 times as much on a protein basis. The reasons for New Zealand's ranking, despite the obvious food surplus, include low GDP per capita, and poor food safety nets - such things as breakfasts in schools. It also fares poorly because of investment in agricultural R\&D.

\section{Productivity and Efficiency}

$\mathrm{R} \& \mathrm{D}$ in the past has resulted in great advances in global agricultural productivity and efficiency.

Research at Carnegie Institute and Stanford University reported in 2010 that agricultural intensification between 1961 and 2005 enabled protection of forests and native grassland. Had these areas been brought into production, an extra 161 gigatonnes of carbon would have been released into the atmosphere. This is over and above the emissions associated with intensification in terms of, for instance, increased fertiliser use.

These calculations support what researchers such as Professor Anthony Trewavas, University of Edinburgh, have been saying for some time - intensification allows protection of the natural environment. Of the 13.5 billion ha of land globally, just over $60 \%$ (approximately 8.3 billion ha) is pasture and woodland, with only 1.6 billion in agricultural use. Only approximately $10 \%$ of the increased growth in food production to feed the predicted 9 billion people by 2050 is expected to come from increasing area of land - most of the growth required is expected to come from intensification.

Intensification must occur within the framework of sustainability.

Considerable effort has gone into trying to define sustainability, and a Google search will result in over 33 million hits. A framework for sustainability, formulated by Smyth \& Dumanski was adopted by the International Soil Science community in 1994. The five components of the framework are:

- Maintaining or improving yield

- Decreasing risks to production
- Preserving resource capacity for the future

- Economically viable

- Socially acceptable

For production agriculture, the inclusion of all components is important - and economic viability is vital for sustaining the agricultural enterprise, noting that in most developed countries, farmers are supported through subsidies (current OECD estimates indicate an average of $18 \%$ of gross farm receipts are government support).

Agriculture in New Zealand is unsubsidised and highly efficient. The OECD Agricultural Outlook 2012 indicates that New Zealand's nutrient surpluses (a surplus equating to a potential loss to the environment) are the lowest in the world. Overseas research confirmed by that in New Zealand shows that we are also in the lowest greenhouse gas production per kilogram of product category (for non-housed animals). Housing animals could reduce still further the GHG emissions as waste products can be trapped and recycled, and may be the way of the future, at least for part of the year or day. Careful management would be required in terms of brand, but given that most northern hemisphere animals are housed for at least part of the time, housing is unlikely to be an issue unless a component of the New Zealand population makes it so.

Water quality is an issue. Nearly a quarter of people replying to the 6th biennial survey of "Public perceptions of New Zealand's environment" released at the end of September 2011 by researchers at Lincoln University, identified water pollution and/or water as the most important environmental issue facing New Zealand. Over $70 \%$ of respondents were on the positive side of the "improved management" balance, and less than $5 \%$ of respondents regarded water quality as bad... but the perception in the media is still that there is a problem and that farmers are causing it.

The reality of water quality in New Zealand is complex and data have been used in many ways to "prove" various things.

The Environmental Performance Index from Yale University is quoted frequently because it ranks New Zealand highly in water quality in comparison with other countries. Actual data reported by the OECD (for the 1980-2004 period; latest data), support the ranking. The Waitaki and Clutha have nitrate concentrations of $0.01 \mathrm{mg} \mathrm{N} /$ litre, and the mighty Waikato is reported to have nitrate concentration of approximately $0.07 \mathrm{mg} \mathrm{N} /$ litre. In Ireland the Barrow had a nitrate concentration of $4.25 \mathrm{mg} \mathrm{N} / \mathrm{litre}$, and in the UK the Thames (upon which the Queen travelled for her 60th Jubilee and Beckham sped with the Olympic torch) was 7.06. The scorecard published by the New Zealand Institute in October using data from NIWA suggest that "nitrate trends in 
New Zealand rivers with the highest concentration" peaked in 2004 at $1 \mathrm{mg}$ nitrate/litre $(0.23 \mathrm{mg} \mathrm{N} /$ litre $)$ and have since reached a plateau.

New Zealand farmers can take a considerable amount of the credit for the fact that rivers and lakes aren't in a worse state. Through levies on their production, they have paid for research and technology transfer. They have also paid directly for on-farm environmentally friendly upgrades; in Europe these activities are subsidised. There is still room for improvement, but implementation of new technologies takes money, time and effort, as well as a willingness to learn and take risks.

Economic viability remains a concern and farmers are constantly looking for different ways to achieve "sustainability"; some appear to be gaining traction.

\section{Approaches to Farming Systems}

The five components of the Sustainability Framework can be met via a range of different farming approaches.

Conventional and organic systems, and the range between the extremes, allow certain inputs in terms of fertilisers and pesticides. Some of these inputs come from a factory, and some are relatively unprocessed - but even "organic" fertilisers and 'cides are increasingly processed in order to improve consistency of desired attributes. There is no consistent, conclusive evidence that organic production systems can yield as highly as conventional systems; research suggests a $40 \%$ decrease in sheep and beef and $20-30 \%$ in dairy. Similarly there is no consistent, conclusive evidence that any of the systems are better for the environment than any of the others based on production. Nor is there any consistent, conclusive evidence that on a per kilo yield basis, less energy is needed, stock is healthier, or soil is more active in terms of bugs.

Comparisons of nutritional composition have shown that there is more variability in food nutrient content to do with cultivar and time of and since harvesting than there is to do with production system pre-farm gate.

Again, the discussion or debates aren't new. The difference in the future is that verification of every system and each claim is likely to be required, and that will be possible only through scientific research and rigorous validation schemes. Validation will enable the added value that the industry is being urged to achieve for commodities.

\section{Agribusiness Futures}

The added-value concept is, again, not new, but has re-surfaced in reports by Coriolus, the New Zealand Institute, the Riddet Institute, KPMG, Pure Advantage and NZTE in the last 12 months. What might be new is government recognition that it can and should contribute to successful industry growth. Research effort is being refocused to support high value industry growth, and there is increased focus on developing the business capabilities to achieve global growth. The Riddet Institute has recommended an increase in research intensity in agri-foods from the present $\$ 350$ million (approximately $0.9 \%$ of total revenue) to $2 \%$ in the short term and $3 \%$ within 5 years. The suggestion is that most of this increase (amounting to $\$ 1$ billion per year by year 5) should come from the private sector, facilitated by the Government. How the increased spend would work is still the subject of debate, but could involve "research vouchers", development grants, and increased spending in the Primary Growth Partnership. Other possibilities include tax credits and tax deductions.

Time, perhaps the next budget, will tell whether any of these suggestions are taken up by the government. What is clear is that the initiative is required: thirty years of urging have resulted in only small gains.

To assist the focus, the Call to Arms suggests the creation of a peak body for agriculture. Echoing Alan Emerson's call for a green table in 2009 in Future Food Farming, and that of KPMG in the Agribusiness Agenda 2012, the peak body or Agri-Food Board would create a strategy for New Zealand agriculture, working with industry and government to determine priorities for growth, $R \& D \ldots$ and enhance the prospects of achieving an overarching agri-food brand as NZ Inc.

\section{Conclusions}

Agribusiness is on the agenda of many organisations, but agribusiness starts on the farm. It requires knowledge, and NZGA is focussed on providing information of value, and assisting with ensuring that advances are disseminated for farmer uptake - assisting with the extra $1 \%$ in productivity gains above what is already being achieved. The conferences, symposia and newsletters that we create are part of the information flow, and are driven by members. The role of NZGA is to assist in improving performance in all aspects of agrifood production. It is the interaction between farmers, researchers, policy analysts and industry personnel that leads to the development of new ideas and resourceefficient thinking that makes a difference.

That difference will allow New Zealand to have a role in feeding the world through sustainable agricultural production systems. The research and development, technology transfer and farm-enterprise resilience that we have already recognised as being vital for improving agricultural productivity have been highlighted as being vital for the world.

Agricultural Outlook 2012 suggests that governments should be setting policy to encourage improved 
agronomic practices, create the right commercial, technical and regulatory environment and strengthen the agriculture innovation system through research, education and extension. All these points have been discussed at past conferences and championed by past presidents.

Addressing these issues will allow New Zealand to regain agri-food leadership in terms of efficient and sustainable innovation value chains, while assisting other countries with improving food security. New Zealand can and should help other countries improve their agribusinesses. At the same time we should be able to leverage intellectual capital offshore to bring benefits for New Zealand and other countries.

Given current understanding - by our markets, developing markets, agribusiness professionals and farmers - it should be a relatively easy move to market New Zealand Food Inc. internationally... except that it requires consolidation. Consolidation is a challenge given the set-up of some of New Zealand's main export industries. Fonterra's global marketing position, and that of Zespri, is considered by the overseas supermarkets to be a hindrance to achieving good prices for their customers. For the New Zealand producer, however, this is an advantage.

The evidence is clear. Times will continue to be interesting and we must move away from energydraining wrangles, establish an Agri-Food Board and concentrate together to achieve a new and improved BAU from what New Zealand does best:

Fresh, minimally processed, high quality food produced in scientifically-founded sustainable fashion in the knowledge that New Zealand farmers are superb managers of intensive production systems, allowing considerable national income to be gained not only from exporting food, but also from tourism based on the managed farmland, water bodies and native landscapes.

\section{Bibliography}

Boven, R.; Harland, C.; Grace, L. 2012. Navigating an uncertain future: environmental foundation for longterm success. $71 \mathrm{p}$.

Economist Intelligence Unit: Global food security index 2012. 20p.

KPMG Agribusiness Agenda 2012. People unlocking the future. 90p. www.kpmg.com/nz/aa2012

Pure Advantage: New Zealand's position in the green race. 60 p. www.pureadvantage.org

Riddet Institute 2012. A Call to Arms: a contribution to a New Zealand Agri-food strategy. 72p. www.riddet. ac.nz

OECD-FAO Agricultural Outlook 2012. Achieving Sustainable Agricultural Productivity Growth. P49-85. 